\title{
Indications for repositioning of blow-out fractures of the orbital floor based on new objective criteria - tissue protrusion volumometry
}

\author{
Daniel Kovar ${ }^{\mathrm{a}, \mathrm{b}}$, Zdenek Voldricha ${ }^{\mathrm{a}}$, Pavel Voska ${ }^{\mathrm{a}}$, Jan Lestak ${ }^{\mathrm{c}}$, Jaromir Astl ${ }^{\mathrm{a}}$
}

Background and Aim. The otolaryngologist often meets with fractures of the orbital floor. The most serious complication is diplopia, arising as a result of herniation of the orbital contents, with or without fixation of the inferior rectus muscle. The aim of our work was to create a mathematical model to calculate the volume of prolapsed soft tissue of the orbit in blow-out fractures, as a factor in deciding on the need for surgical treatment.

Patients and Methods. In a retrospective study (2007-2013), we evaluated 80 patients with blow-out fractures, divided into two equal groups: 40 conservatively treated and 40 surgically treated patients. We created the model by measuring the fracture lines and herniation of the orbital soft tissues in the coronal and sagittal sections from CT images, equivalent to half the volume of a rotating ellipsoid.

Results. According to the proposed model, posterior and anterior fractures with a prolapse volume above $500 \mathrm{~mm}^{3}$, and anteroposterior fractures with a volume over $1400 \mathrm{~mm}^{3}$, are indicated for surgery.

Conclusion. The volume of prolapsed soft tissue relative to the location of the fracture is the main indicator for selecting the best treatment procedure immediately after injury.

Key words: blow-out fractures, volumometry, diplopia, CT-assisted surgery

Received: March 21, 2017; Accepted with revision: August 22, 2017; Available online: August 31, 2017

https://doi.org/10.5507/bp.2017.036

${ }^{a}$ Department of ENT and Maxillofacial surgery, $3^{\text {rd }}$ Faculty of Medicine, Charles University in Prague and Military University Hospital

Prague, Czech Republic

${ }^{b}$ Faculty of Military Health Science in Hradec Kralove, University of Defence, Hradec Kralove, Czech Republic

'Eye Clinic FBMI CVUT Prague, Czech Republic

Corresponding author: Daniel Kovar, e-mail:daniel.kovar.dk@gmail.com

\section{INTRODUCTION}

The concept of a hydraulic, retromarginal orbital fracture (blow-out fracture) first appeared in the world literature in the work of Smith and Regan ${ }^{1}$ in 1957. Today, the most accepted explanations for the fracture ${ }^{2,3}$.

1. Following a blunt blow to the flexible, incompressible eyeball, transfer of pressure occurs causing a fracture of the lower and/or medial walls of the orbital floor.

2. Following force on the lower orbital edge (without causing it to fracture) a pressure wave spreads through the bone and causes it to break at the point of thinning, therefore most often in the medial part of the base of the orbit.

Orbital injuries make up about $40 \%$ of all fractures of the facial skeleton, and $67-84 \%$ of these are retromarginal orbital fractures. The locus minoris resistentiae of the orbital floor is located medially from the canalis nervus infraorbitalis and is only 0.07 to 0.2 millimeters thick ${ }^{4}$.

Clinical manifestations of these fractures include edema, hematoma and emphysema of the eyelids and orbits, neuropathy (most commonly hypoesthesia) in the $\mathrm{n}$. Infraorbitalis. Depending on the time lapse since the accident, exophthalmos, the normal positioning of the eyeball and enophthalmos can all be observed. The most important symptoms are limited motility and diplopia, most often caused by myogens and mechanical lesions. Traumatic changes affect the inferior rectus muscle, the inferior oblique muscle and the medial rectus muscle.

Symptoms may be seen in various combinations or almost without them. The presence of an orbital floor fracture, its size and weight, are determined by CT imaging (coronal and sagittal sections). If the patient is asymptomatic or the symptoms quickly disappear (with the exclusion of muscle entrapment) and late onset diplopia does not occur, we would take a conservative approach to the fracture. In other cases surgical revision would be used. Due to the possibility of direct spread of infection to the sterile environment of the orbit, the procedure is carried out under blanket antibiotic treatment (Holý, Kovář).

Surgical solutions for fractures of the orbital floor are important mainly because of persistent diplopia, which can significantly limit a patient's quality of life. Independently occurring enophthalmos and numbness in the infraorbital nerve are less important.

In our previous works, we focused on anatomical and functional results in operated patients with fractures of the orbital floor in relation to the access routes, types of fixation materials, the use of CT-guided surgery and the proper timing of surgical treatment ${ }^{5,6}$.

In the past, the only indication for surgical treatment of these fractures was the clinical finding and its evolution over time. At the time there was no quantification of the post-traumatic state. 


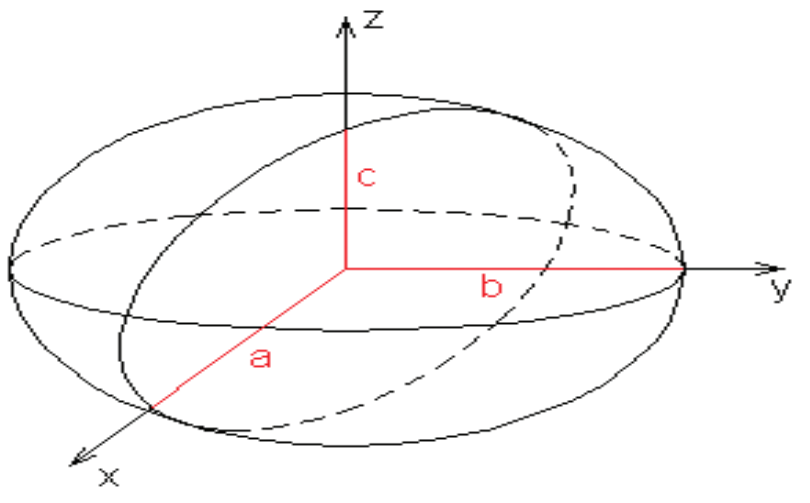

Fig. 1a. Rotating ellipsoid.

\section{OBJECTIVES}

To develop objective criteria for the indication of surgical treatment of blow-out fractures using a spheroid model.

To determine the volume of prolapsed orbital soft tissue into the maxillary sinus as a factor in predicting the necessity for surgical treatment.

To indicate patients with blow-out fractures in a correct and timely manner for surgical intervention to ensure the most effective reconstruction of the anatomical shape of the orbital floor.

\section{PATIENTS AND METHODS}

In our department from 2007 to 2013, we treated 80 patients with blow-out fractures of the orbital floor, 40 (50\%) of whom were treated surgically. We confirm, that IRB was given for our study.

The ratio of males to females was $2: 1$, with a slight predominance of the right orbit. The average age of the patients was 40 years (16-85 years), those who were not operated were monitored until the disappearance of the diplopia, while operated patients were monitored on a regular basis: 1 week, 1 month, 3 months, 6 months and 1 year after surgery. The mechanism of injury most often involved direct blows, followed by falls, sports injuries and car accidents (Table 1).

Surgical revision of blow-out fractures was indicated

Table 1. Mechanism of injury.

\begin{tabular}{lcccc}
\hline $\begin{array}{l}\text { Mechanism } \\
\text { of injury }\end{array}$ & Blows & Falls & $\begin{array}{c}\text { Sports } \\
\text { injuries }\end{array}$ & $\begin{array}{c}\text { Car } \\
\text { accidents }\end{array}$ \\
\hline Rate $(\%)$ & 60 & 15 & 15 & 10 \\
\hline
\end{tabular}

in clinically significant enophthalmos associated with a defect in the orbital floor (detected by CT scan) and accompanied by diplopia, in cases of persistent double vision after recovery from edema of orbital soft tissue, in the entrapped inferior rectus muscle confirmed with CT, in cases of a positive passive duction test and even when theorbital contents were endangered by bone fragments.

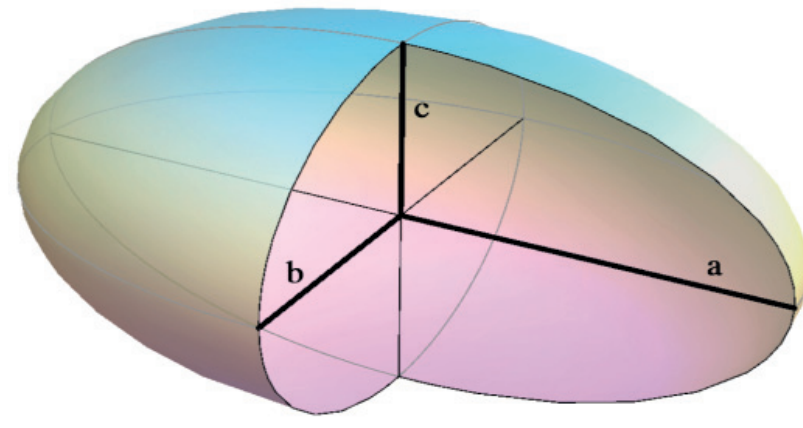

Fig. 1b. Rotating ellipsoid.

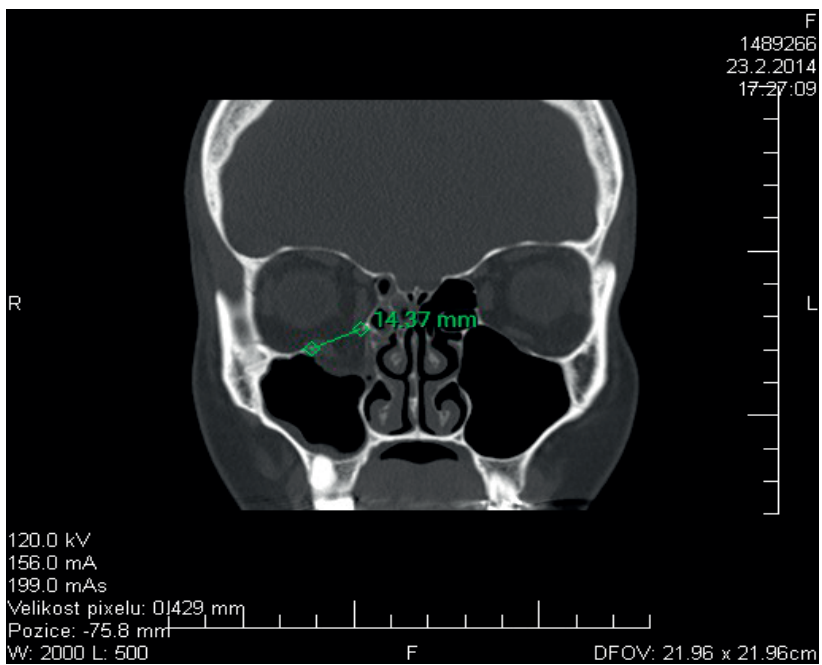

Fig. 2. Measurement through coronal.

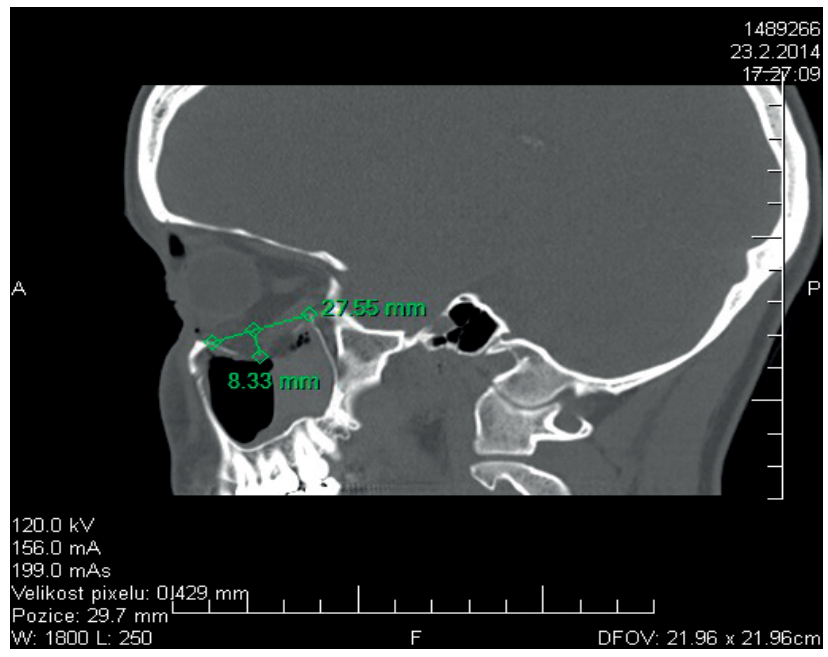

Fig. 3. Measurement through sagittal section. section.

Given our experience with the surgical and non-surgical treatment and long-term follow-up in patients recovering after fractures of the orbital floor ${ }^{7}$, we decided, in addition to the normal clinical indication criteria for surgery of blow-out fractures, to create a mathematical model for calculating the volume of prolapsed orbital soft tissue and to determine the critical volume values, which would 
Table 2. Prolapsed volumes in blow-out fractures/conservative therapy.

\begin{tabular}{|c|c|c|c|}
\hline \multicolumn{4}{|l|}{ Conservative Approach } \\
\hline Fracture location & Anterior & Posterior & Anteroposterior \\
\hline Volume $\left(\mathrm{mm}^{3}\right)$ & $90(44-128)$ & $140(114-156)$ & $433(345-474)$ \\
\hline
\end{tabular}

Table 3. Prolapsed volumes in blow-out fractures/surgical therapy.

Surgical Approach

\begin{tabular}{l|c|c|c}
\hline $\begin{array}{l}\text { Fracture location } \\
\text { Volume }\left(\mathrm{mm}^{3}\right)\end{array}$ & Anterior & Posterior & Anteroposterior \\
$1827(1402-2182)$ \\
\hline
\end{tabular}

Table 4. The frequency of blow-out fractures by location and the relationship between conservative and surgical therapy.

\begin{tabular}{|c|c|c|c|c|c|c|}
\hline \multirow{2}{*}{$\frac{\text { Fracture location }}{\text { Treatment }}$} & \multicolumn{2}{|c|}{ Anterior (19), 24\% } & \multicolumn{2}{|c|}{ Posterior (28), $35 \%$} & \multicolumn{2}{|c|}{ Antero-posterior (33), $41 \%$} \\
\hline & Conserv. & Surgical & Conserv. & Surgical & Conserv. & Surgical \\
\hline No. of fractures & 17 & 2 & 15 & 13 & 8 & 25 \\
\hline No. of fractures (\%) & $89 \%$ & $11 \%$ & $54 \%$ & $46 \%$ & $24 \%$ & $76 \%$ \\
\hline
\end{tabular}

in turn support the indication for surgical treatment in the immediate post-traumatic period.

We retrospectively evaluated the clinical findings (post-traumatic and after healing) of the groups of patients described above from 2007 - 2013, in relation to CT images and after calculating the volume of the prolapsed tissue of the orbit. The main measure of success of the treatment process was the disappearance of diplopia.

The mathematical model is equal to a half-volume rotating ellipsoid (Fig. 1a and 1b), where the the lower surface of the fractured orbital floor forms the base and the separate dimensions are obtained from coronal and sagittal sections (Fig. 2 and 3).

For each patient in the two groups, we carried out a triple measurement of individual lengths of the fracture line, calculated the arithmetic average and recorded the position of the fracture (anterior, posterior and anteroposterior).

The formula for calculating the volume of the spheroid is $\mathrm{V}=4 / 3 \pi \mathrm{abc}$, ie for its half after readjustment: V1 / 2 $=4 / 6 \pi \mathrm{abc}(2 / 3 \pi \mathrm{abc})$.

\section{RESULTS}

The resulting volumes of prolapsed orbital soft tissue in conservative and surgical methods of treatment are shown in the tables below (Table 2 and 3 ).

In anteroposterior fractures (76\% of which required operating) we recommend surgery in prolapse greater than $1400 \mathrm{~mm}^{3}$, and in anterior (operated only in $11 \%$ of cases ) and posterior fracture types (operated in $46 \%$ of cases) in prolapse over $500 \mathrm{~mm}^{3}$ after remission of acute swelling, if no urgent (Table 4, Fig. 4).

\section{Blow-out fractures (80), $100 \%$}

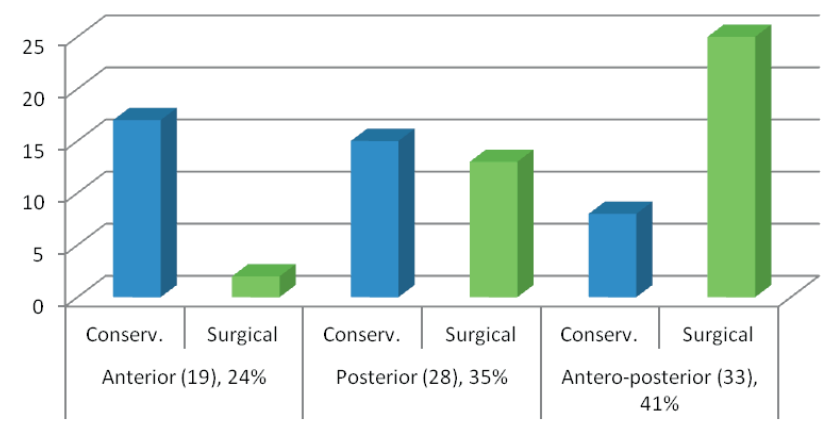

Fig. 4. Relationship between conservative and surgical therapy and fracture location.

\section{DISCUSSION}

A number of Czech and foreign authors have addressed the issues of the appropriate timing for and method of surgery in blow-out fractures. Indications for surgical treatment are currently based on clinical symptoms, ophthalmological findings and developments in the immediate post-traumatic period.

If no urgent operation is indicated, then the decision of whether to operate depends on the development of clinical symptoms and the total volume of prolapsed orbital tissue. Due to the shadow of the upper jaw, ultrasound volumometry cannot be used.

Harris, in line with most surgeons ${ }^{5,7-11}$ recommends surgery for defects of the orbital floor where clinically significant enophthalmos can be expected or in persisting diplopia 14 days post-accident.

With many years experience in orbital surgery, we have good understanding of the proper timing for surgical intervention. Two weeks are enough for the orbital hematoma and edema to subside or reduce and to prepare the patient for surgery ${ }^{4}$. 
Kwon et al. divided orbital floor fractures into anterior, posterior and anteroposterior ${ }^{12}$. But there is a very large dispersion of functional results, 8.7-67\%, especially in the persistence of postoperative diplopia ${ }^{5,713-17}$. Worth noting is the contribution of CT-guided surgery, leading to the complete disappearance of postoperative diplopia. The first functional results with $\mathrm{CT}$ navigation were not published until 2014 (ref. ${ }^{5-6)}$.

Beumer, Pham and Schramm ${ }^{18-20}$ recommend the use of CT navigation in maxillofacial bone fractures to minimize post-traumatic enophthalmos and for improved facial symmetry.

\section{CONCLUSION}

Given that on average only $50 \%$ of patients with orbital floor fractures require surgical treatment, it is desirable to be able to predict these patients immediately after the injury. Clinical sequelae shortly after injury include hematoma, pneumoorbit and, subcutaneous emphysema, which usually change the clinical picture towards the expected pathology (which subsides in a few days), or they appear falsely to be functionally insignificant (latent symptoms). The proposed calculation of the volume of herniated soft tissues of the orbit helps us considerably in the selection of treatment.

The accuracy of our mathematical model is supported by excellent anatomical and functional results with minimal permanent diplopia, based on experience with CT navigated and video assisted CT-assisted surgery and consistent, long-term monitoring of patients, including outcomes in conservative treatment. Since 2014 we have indicated patients with orbital floor fractures for surgery based on clinical criteria and mathematical calculation.

Author contributions: DK: reviewed the literature and drafted the manuscript. All authors contributed equally to data collection, analysis, interpretation and correction of the final manuscript version.

Conflict of interest statement: The authors state that there are no conflicts of interest regarding the publication of this article.

\section{REFERENCES}

1. Smith B, Regan W. Blow-out fractures of the orbit. Am J Ophthamol 1957;44:733-9.

2. Fujino T. Mechanism of orbital blow-out fracture. Jap J Plast Reconstr Surg 1974; 17:427-34.

3. Green RP, Peters DR, Shore JW. Force necessary to fracture the orbital floor. Ophthal Plast Reconstr Surg 1990;21:211-7.

4. Kovář D, Voldřich Z, Voska P, Lešták J, Drahokoupilová E. Effect of CT Navigation in Surgery of Blow-out Fractures of th Orbital Floor on Functional and Anatomical Results. Ind J Appl Res 2014;4:23-7.

5. Kovář D, Voldřich Z, Voska P, Lešták J, Drahokoupilová E. Videoassisted and CT navigated reposition of an orbital blow-out fracture. Mil Med Sci Lett (Voj Zdrav Listy) 2014;83:145-50.

6. Cigánek L, Voldřich Z, Lešták J. Diplopia in blow-out fractures (In Czech). Čs Oftal 1990;46:139-44.

7. Harris GJ. Orbital blow-out fractures: surgical timing and technice. Eye 2006;20:1207-12.

8. Harris GJ, Garcia GH, Logani SC, Murphy ML, Sheth BP, Seth AK. Orbital blow-out fractures: Correlation of preoperative computed tomography and postoperative ocular motility. Tr Am Ophth Soc 1998;XCVI:329-47.

9. Burnstine MA. Clinical recommendations for repair of isolated orbital floor fractures: an evidence-based analysis. Ophthalmology 2002;10:1207-13.

10. Chrobok V, Vokurka J, Čelakovský P, Růžička J, Juran J. Orbital fractures and their influence of the position and mobility of the eyeball (In Czech). Choroby hlavy a krku 1998;7:5-12.

11. Ceylan OM, Uysal Y, Mutlu FM, Tuncer K, Altinsoy HI. Management of diplopia in patients with blowout fractures. Indian J Ophthalmol 2011;59:461-4.

12. Kwon JH, Kim JG, Moon JH, Cho JH. Clinical analysis of surgical approaches for orbital floor fractures. Arch Facial Plast Surg 2008;10:214.

13. Gunarajah DR, Samman N. Biomaterials for repair of orbital floor blowout fractures: a systematic review. J Oral Maxillofac Surg 2013;71:550-70.

14. Hrušák D, Jambura J, Hauer L. Blow-out fractures Fractures of the Orbital Floor (Statistics) (In Czech). Čes Stomat 2010;110:104-8.

15. Chi MJ, Ku M, Shin KH, Baek S. An analysis of 733 surgically treated blowout fractures. Ophthalmologica 2010;224:167-75.

16. Jin HR, Lee HS, Yeon JY, Suh MW. Residual diplopia after repair of pure orbital blowout fracture: the importance of extraocular muscle injury. Am J Rhinol 2007;21:276-80.

17. Loba P, Kozakiewicz M, Nowakowska O, Omulecki W, BroniarczykLoba A. Management of persistent diplopia after surgical repair of orbital fractures. J AAPOS 2012;16:548-53.

18. Beumer HW, Puscas L. Computer modeling and navigation in maxillofacial surgery. Curr Opin Otolaryngol Head Neck Surg 2009;17:2703.

19. Pham AM, Rafii AA, Metzger MC, Jamali A, Strong EB. Computer modeling and intraoperative navigation in maxillofacial surgery. Otolaryngol Head Neck Surg 2007;137:624-31.

20. Schramm A, Suarez-Cunqueiro MM, Rücker M, Kokemueller $H$, Bormann KH, Metzger MC, Gellrich NC. Computer-assisted therapy in orbital and mid-facial reconstructions. Int J Med Robotics Comput Assist Surg 2009; 5:111-24. 